\title{
FIGURINO DE CINEMA E IMAGEM FEMININA'
}

\section{Andreana Alba Nery de Mello Buest ${ }^{2}$ Marilia Gomes de Carvalho ${ }^{3}$}

\section{Resumo}

Marlene Dietrich, Greta Garbo, Joan Crawford e Rita Hayworth. Símbolos do cinema, representantes da estratégia de penetração ideológica do "american way of life", discurso sóciocultural globalizante da indústria cinematográfica de Hollywood. Veículo dos fazeres globais, da visão de mundo norte-americana, impondo aos saberes locais seu estilo de vida e reafirmando sua política de intervenção. O artigo enfoca a supervalorização de características físicas femininas na construção de sua imagem cinematográfica. A análise semiótica, fenomenológica e os estudos de gênero foram as perspectivas utilizadas para demonstrar as influências do uso do figurino como sistema de signos.

Palavras-Chave: figurino, figurino e moda, mulher no cinema.

\section{INTRODUÇÃO}

O figurino transmite mensagens e características psicológicas, sociais e culturais como a roupa da vida real; comunica o status, a condição emocional, a situação do usuário. O figurino transporta o ator para o mundo da personagem.

Este artigo apresenta os resultados de uma pesquisa realizada sobre o papel do figurino na construção da imagem feminina no cinema hollywoodiano das décadas de 30 e 40.

A seleção dos filmes foi feita considerando a presença de atrizes que se enquadrassem no modelo de imagem feminina estudado e que apresentassem notoriedade e aproximação com o universo da moda. A acessibilidade às informações e a delimitação temporal foram estabelecidas como critérios para a escolha dos filmes. Por meio de uma pesquisa histórica, determinou-se que os filmes dos anos 30 e 40 seriam estudados, por pertencerem a um período de grande importância e influência cultural do cinema de Hollywood.

As questões iniciais que orientaram os objetivos da pesquisa foram: Qual o papel do figurino na construção da imagem da atriz de Hollywood? Qual a relação do figurino com a roupa do dia-a-dia? O figurino tem influência na construção da beleza feminina no cinema deste período?

Este artigo apresenta a síntese da análise e dos resultados obtidos com o primeiro filme: Blonde Venus (A Vênus Loira, 1932) com Marlene Dietrich. Os

1 Artigo apresentado no Encontro Internacional Fazendo Gênero VI, que ocorreu em Florianópolis, nos dias 10 a 13 de agosto de 2004.

2 Mestranda em Tecnologia pelo Programa de Pós-Graduação em Tecnologia do Centro Federal de Educação Tecnológica do Paraná PPGTE/CEFET-PR. Bacharel em Estilismo, professora do Curso de Design de Moda da Universidade Tuiuti do Paraná e do Lady \& Lord Professional School e pesquisadora do Grupo de Estudos e Pesquisas sobre Relações de Gênero e Tecnologia - GeTec. E-mail: aabuest@terra.com.br.

3 Doutora em Antropologia Social, professora do PPGTE / CEFET-PR, coordenadora e pesquisadora do GeTec. 
outros filmes analisados, cujos resultados não serão apresentados neste artigo, foram: Grand Hotel (1932), com Greta Garbo; Possessed (A Possuída, 1931) com Joan Crawford, e Gilda (1946), com Rita Hayworth.

A análise do figurino dos quatro filmes considerou a estrutura da roupa (o corte e a modelagem), os tecidos utilizados (caimento, textura, estampas) e os acessórios e complementos (calçados, jóias, chapéus, luvas, penteados). A abordagem semiótica permitiu o estudo do figurino, presente nas seqüências das cenas dos fitmes, em um processo dialético: a análise de cada uma de suas partes, o relacionamento entre elas e a extração de um significado. $O$ figurino analisado, o contexto e a imagem feminina do filme foram submetidos às teorias do estudo da imagem de Martine Joly (1996), a teoria do vestuário como uma linguagem trabalhada por Alison Lurie (1997), a questão feminista encontrada em Laura Mulvey (1973), do consumo conspícuo de Thornstein Veblen (1899) e algumas idéias a respeito da beleza de Nancy Etcoff (1999), que formaram a base teórica da análise do figurino nos filmes selecionados, atrelados às questões da globalização e da tecnologia. Na tentativa de buscar paralelos das representações da mulher no cinema de Hollywood em épocas diferentes, imagens das décadas de 30 e 40 foram confrontadas com imagens de algumas atrizes atuais.

\section{Resultados - MARLENE DIETRICH EM BLONDE VENUS, 1932}

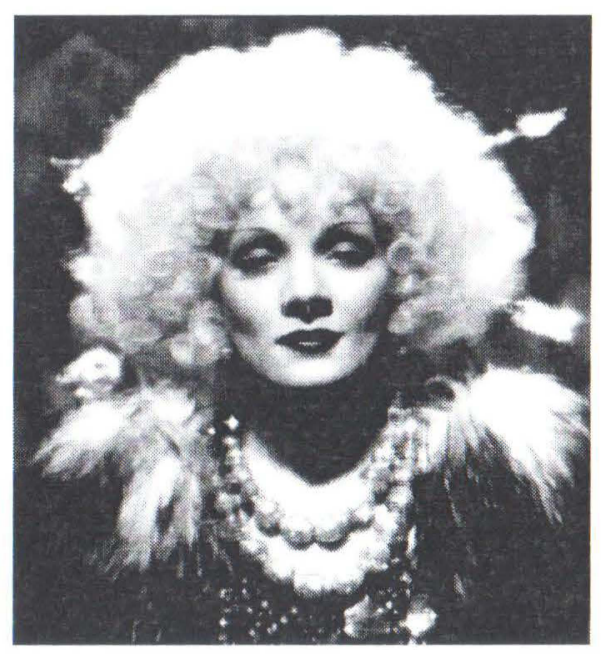

Figura 1 - STILL DE "BLONDE VENUS" FONTE: IMBD

A narrativa está contextualizada entre a $1^{\circ}$ Guerra Mundial e a Depressão Norte-Americana. A família de Helen Faraday, personagem de Marlene Dietrich, passa por dificuldades financeiras, que se agravam com a doença de seu marido, Edward Faraday. Marlene interpreta uma mãe carinhosa, cuidadosa e devotada que, como toda mulher desta época, precisa trabalhar. 
Combinando uma aura sexy e intima, misteriosa e transgressora, Dietrich encanta o espectador com duas personalidades opostas e conflitantes: a imagem de mãe e de mulher sensual, provocativa.

$1^{\text {a }}$ cena: mulheres nadam nuas em um lago - uma delas é Helen. Elas são espionadas pelos personagens masculinos e pelo espectador. Marlene Dietrich se aproxima dos homens para conversar. Ela rompe o espaço seguro dos olhares masculinos e encara o grupo / o espectador.

Figurino: é a própria água do rio, transparente e em movimento, associada à fonte de vida, meio de purificação e de regeneração. Os rios são os agentes de fertilização que conduzem a água, são caminhos, destinos, a correnteza que orienta o ser humano; é também um obstáculo e a possibilidade de vida ou de morte. É nesse momento que Helen deixa a vida noturna para casar com Edward.

$2^{\mathrm{a}}$ cena: Helen, mãe e dona de casa.

Figurino: Da água do rio à água da banheira de seu filho. Helen veste uma camisa branca de manga dobrada, saia preta e avental. O figurino sugere empenho, dedicação e comprometimento - "arregaçar as mangas". O avental, associado ao trabalho, aprendizado, serviço bem realizado, é peça que esconde as partes sexuais.

$3^{\text {a }}$ cena: Volta aos palcos.

Figurino: Para sustentar a família Helen Faraday procura emprego em cabarés. Em sua primeira entrevista usa um vestido simples, de tecido barato, que se abre a partir dos joelhos. Esse figurino está descontextualizado, fora da atmosfera do lar - ele está em um ambiente não doméstico, de luxo, glamour e fantasias. Por cima, um tailleur acinturado, com recorte na frente e atrás, insinua uma casaca masculina e cobre o vestido simples.

Na gola e nos punhos a peça é ornada com 'mink!', material conspícuo associado à riqueza da produção do filme, ao selvagem e ao lado indomável da personagem e da atriz.

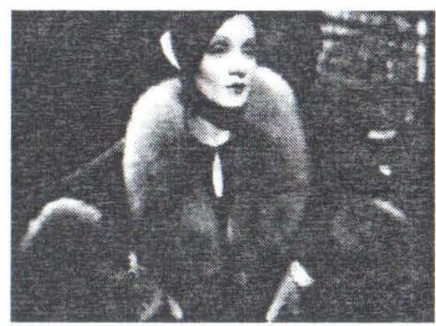

Figura 2 - ENTREVISTA DE EMPREGO FONTE: IMBD

A repetição de algumas peças de roupas durante o filme, como o vestido preto, o casquete com detalhes brancos, o tailleur com peles da segunda cena e as roupas que ela usará durante sua fuga, aparecem nos momentos de fraqueza e de sofrimento da personagem. 
4 cena: No camarim.

De frente para o espelho Marlene acrescenta a máscara de uma nova personagem que surge dentro de Helen Faraday - a Blonde Venus. Esse processo, a maquiagem, a colocação da peruca, é mostrado para o espectador por meio do espelho - símbolo de outra vida, outra realidade. A imagem final não é a da personagem, nem a de Marlene, mas de uma personagem da personagem, uma mulher que engloba todas e nenhuma - o real e a mentira.

5" cenå: O Show "Hot Voodoo".

Figurino: Este número é encenado por dançarinas negras, com perucas de estilo 'afro' e pele pintada, usando colants de paetês adornados por penas na cintura. Seguram escudos e trazem consigo um gorila acorrentado. $O$ macaco sobe ao palco e as dançarinas se posicionam no fundo. O macaco olha para o público à sua frente (encara o espectador) e retira vagarosamente uma das mãos, surge uma outra mão - feminina. Retira a cabeça e surge a Blonde Venus, nascida de uma fera, de um animal selvagem e macho. Como em um streap tease, Blonde Venus retira o corpo do macaco, a fantasia, o masculino e o feminino se revelam completamente. A peruca loira possui duas flechas que se cruzam, representando o pensamento, a luz, asabedoria. Exibe plumas de aves raras na cintura e nos ombros, criando uma ombreira, símbolo de poder e força.

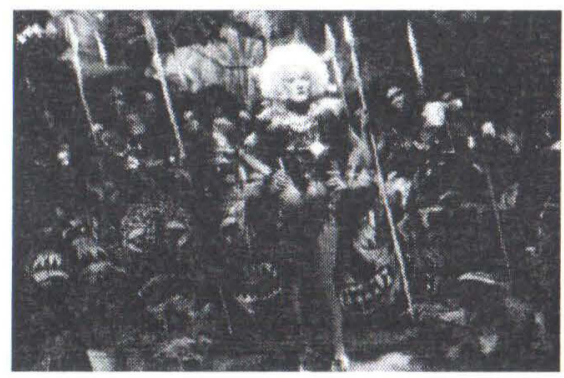

Figura 3 - "HOT VOODOO" FONTE: IMDB

As penas são associadas aos rituais de ascensão divina no xamanismo, ao crescimento da vegetação, ao poder aéreo, distante deste mundo. As plumas da Blonde Venus valorizam sua aura de divindade, remetendo à deusa Vênus. Seu colant é adornado com pedras representando uma armadura, um espartilho, uma estrutura que modela o corpo e reluz com o movimento, sustenta o busto e valoriza suas características femininas.

5a cena: Cary Grant (Nick Towsend) visita Helen Faraday após o show.

Figurino: A Blonde Venus mantém a roupa, mas troca a peruca loira por um chapéu estilo militar enfeitado com plumas altas; é Helen novamente. Sua imagem impressiona o personagem masculino e o espectador. Como a dominadora fetichista, protegida em sua couraça, ela incorpora uma fantasia que cria imagens ilusórias, usadas para seduzir Nick Towsend, um político poderoso. 


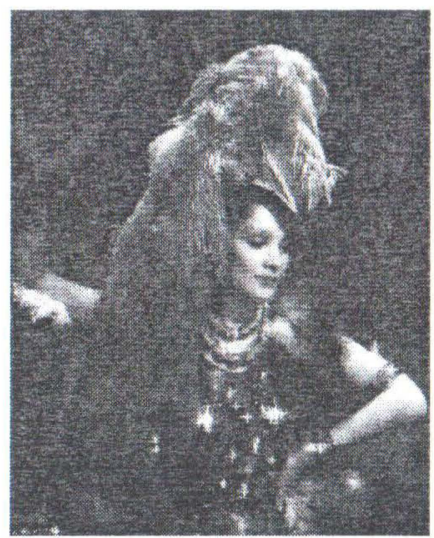

Figura 4 - HELEN FARADAY FONTE: IMDB

6 cena: Helen Faraday e Nick Townsend - amantes.

Figurino: Vestindo uma capa de gabardine e um chapéu de abas, sugerindo camuflagem e proteção, a protagonista se despede do marido no cais. A capa sempre foi usada no cinema como elemento que esconde a identidade, as intenções, por isso é essencial aos detetives e super-heróis.

\section{$7^{\text {a }}$ cena: Viagem.}

Figurino: Casaca, culote, colete, chapéu, botas e chicote. Traje masculino completo de montaria, em preto. Helen mantém a postura da dominadora e manipula um chicote durante todo seu diálogo com Nick. O chicote entra como um elemento punitivo e fetichista, que remete à relação de dominação, obediência, senhor, escravo. Helen se une a Nick por motivos financeiros; entretanto sua atitude valorizada pelo figurino confunde o espectador: Quem é o proprietário?Quem é a propriedade?

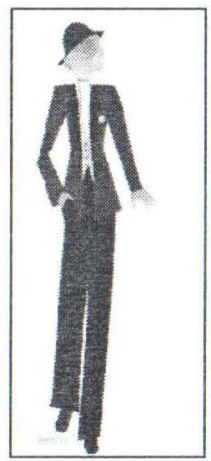

Figura 5 - $A$ VIAGEM

FONTE: $A$ autora

NOTA: As ilustrações apresentadas neste artigo foram criadas pela autora para auxiliar a visualização do figurino analisado. 
8 cena: Reencontro e Fuga.

Figurino: Durante uma discussão com Edward, a personagem usa um vestido leve, longo com bordados, demonstrando vulnerabilidade e feminilidade, mas sobre o vestido usa uma ameaçadora estola de pele que envolve seus braços, sobe por trás de sua cabeça e fecha o colo. O figurino tenso (contraste entre tecido leve e pesado) transmite o momento que precede um conflito entre Helen e Edward pela posse do filho. Num rompante ela toma seu filho e iniciam a fuga.

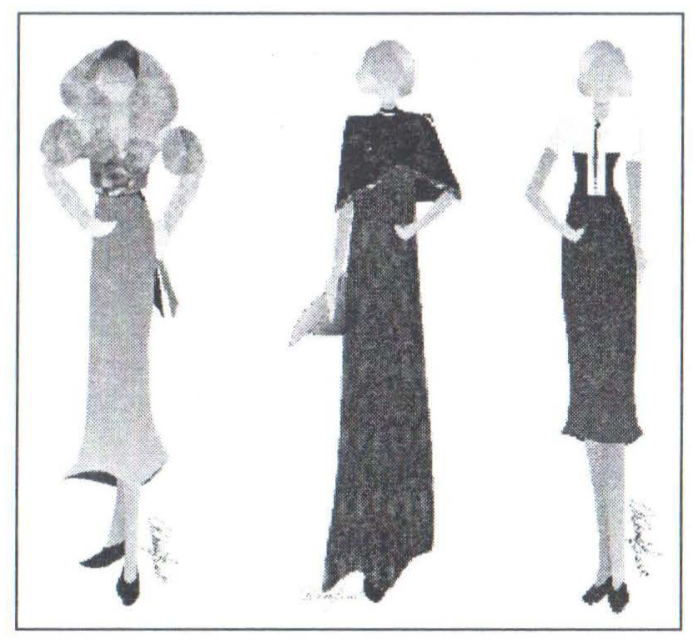

Figura 6 - A BRIGA COM EDWARD E A FUGA FONTE: $A$ autora

9a cena: Fuga.

Nas cenas seguintes Helen sustenta a si e a seu filho realizando performances em diversas boates do interior. Foge sempre que o marido a localiza. Ela já não consegue manter as duas personagens.

Figurino: Seus vestidos são modestos e de modelagem mais simples, sem glamour, sem brilhos ou peles. O figurino representa a ausência da Blonde Venus, é Helen quem está no palco.

10aㅡ cena: Helen entrega seu filho ao pai, Edward.

Figurino: Helen desiste e pelo bem do menino o entrega ao pai. Frustrada, depressiva, angustiada, seu figurino é uma mistura tecidos e estampas conflitantes. Blusas rasgadas de bolinhas, echarpe xadrez ou de bolas, lenço listrado, chapéu de abas largas e pesadas, criam uma figura mais baixa, encolhida, sofrida. Os sapatos gastos indicam a dor e a falta de rumo da personagem. 

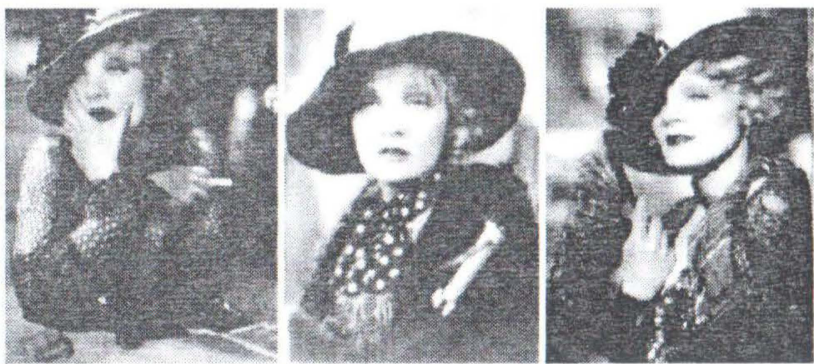

Figura $7-A$ TRISTEZA DE HELEN

FONTE: IMDB

11' cena: Helen Jones, o iceberg de Paris.

Figurino: Em Paris uma nova personagem aparece. Vestida como um homem, de casaca branca e cartola, Helen Jones flerta com as garotas do palco antes de cantar I Couldn't Be Annoyed, que ficou conhecida como "a cena lésbica" do filme.

Helen representa a imagem masculina dominante. Ela está vestida não como um homem comum, mas como um cavalheiro, rico e refinado. Cartola e casaca são elementos associados não apenas com a riqueza, mas com a nobreza material e de atitudes. A cor branca designa riqueza, pois é de difícil conservação.

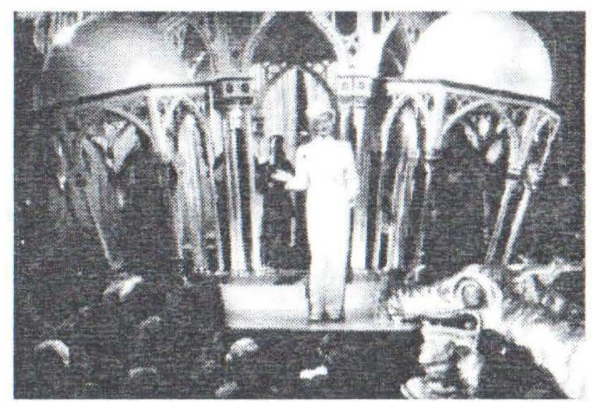

Figura 8 - SHOW "I COULDN'T BE ANNOYED" FONTE: IMDB

12 ${ }^{\text {a }}$ cena: O casamento de Helen e Nick.

Figurino: Os jornais anunciam o casamento e Helen aparece em uma foto usando uma casaca preta, provocadora e masculina. $O$ refinamento do branco foi substituído pelo mistério do preto. Rica e poderosa, Helen volta ao antigo lar para buscar o filho. Usa um vestido de cetim preto em estilo oriental e um casaco com bordados em uma faixa que desce da gola a barra.

$\mathrm{O}$ vestido tem uma modelagem ousada, apresenta recortes no colo e nas costas deixando à mostra ombros e pescoço - vulnerabilidade. 


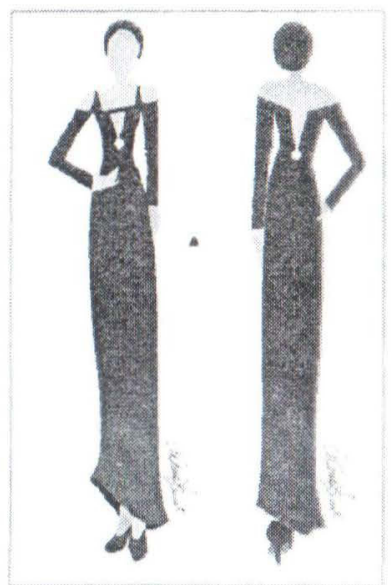

Figura 9-CETIM PRETO FONTE: $A$ autora

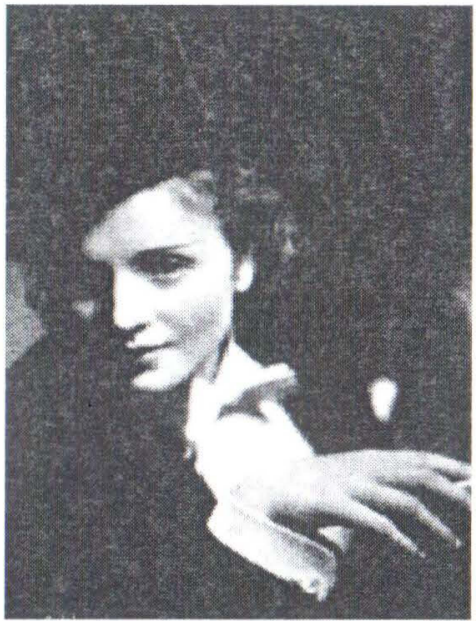

Figura 10 - ANÚNCIO DO CASAMENTO FONTE: IMDB

Em Fetiche: moda, sexo e poder, V. Steele (1997) ressalta a característica fetichista do cetim que remete, no toque e na textura visual escorregadia e macia, à pele feminina. A sensualidade de Helen reconquista o marido. Reassumindo suas características hiperfemininas, envolta em uma aura de beleza e ternura e tendo cumprido seu castigo, ela é finalmente "perdoada" por Edward e pelo espectador.

Desde o começo de sua carreira, Marlene Dietrich inovou, ultrapassou, cruzou a barreira do gênero como ninguém antes dela. Vanguardista, masculina / feminina, era uma das poucas atrizes que criava seus próprios trajes. Seu visual andrógeno e conflitante era a parte mais importante de seu mito, de sua imagem e pode ser encontrado em Morocco (1930), ou Dishonored (1931) em que usa um terno de couro com elementos extremamente masoquistas. Em Shanghai Express (1932) se apossa do quepe militar do seu companheiro de cena e em Seven Sinners (1940) veste um uniforme da marinha. Vestindo roupas de homem, fazendo cenas de nudez e desafiando a imagem-padrão da mulher no cinema (e na vida real), Marlene Dietrich se tornou um símbolo de bad girl, venerada como uma deusa a ser temida.

\section{IMAGEM}

Imagem é um instrumento de comunicação que se associa ou se confunde com o que representa. No universo das imagens cinematográficas, o espectador se depara com a ficção, com informações montadas para criar uma outra significação e se esquece de seu caráter construído. 
Neste contexto, as imagens construídas das atrizes passaram a representar o estilo de vida feminino do ocidente (dos Estados Unidos) e se estabeleceram no imaginário do espectador como representações e símbolos pertencentes a uma convenção sóciocultural estabelecida. Rostos, corpos, estilo de vida, roupas e frases se tornaram novos símbolos da sociedade.

A mulher está no centro das imagens em movimento, associadas ao deus Eros, ao voyeurismo. Nas décadas de 30 e 40 o olho da câmera era masculino, refletindo um comportamento sóciocultural global. A mulher no filme sabe-se observada pelo espectador que se identifica com o personagem. Assim, suas características hiperfemininas eram valorizadas e potencializadas para entreter o protagonista / espectador masculino, reiterando referenciais corpóreos das mulheres jovens: busto grande, firme e empinado: a cintura delineada (centro do corpo); pernas bem torneadas; quadris largos indicando alta quantidade de estrogênio; o cabelo sedoso.

$\mathrm{Na}$ década de 30 as atrizes eram apresentadas com maquiagens dramáticas, roupas fabulosas e poses elaboradas diante dos filtros das câmeras. A beleza natural era obtida por meio de artifícios: cortes, deslocamentos e desvios. A câmera e o figurino camuflavam o explícito e exacerbavam o desejo. O olhar masculino usava primeiros planos e 'closeups', uma lupa imaginária do espectador que se aproximava e investigava os pedaços da imagem feminina de maneira anatômica. Construíam-se assim os símbolos de beleza, representantes hegemônicos de uma realidade dominante, idealizados, moldados e construídos para atrair.

A beleza feminina fragmentada, criada por Hollywood, é obtida com o uso de dublês de corpo (pessoas com corpos "perfeitos") que são combinados com rostos belos de atores e atrizes. O espectador funde as partes e conserva uma imagem composta, montada, virtual, irreal, porém perfeita, divina e bela. A explosão das imagens femininas no cinema é um efeito perverso, a subordinação à beleza com regras.

Em Dress as an Expression of the Pecuniary Culture, T. Veblen (1989) destaca uma das características da sociedade patriarcal na qual a mulher tola e bela é o objeto máximo de consumo conspícuo. O poder masculino (econômico e sexual) está representado nas mulheres jovens, ociosas, vestidas como mais um item de luxo, na vida real ou no ambiente da ficção.

\section{O FIGURINO}

O figurino feminino de cinema foi analisado como ferramenta de reforço de padrões estéticos e de beleza, que possui uma relação visual muito intensa com o espectador'e com as personagens. Uma roupa teatral, de mentira, que pode ser considerado um sistema de signos, um conjunto de objetos.

Na diegése, na seqüência narrativa, a denotação é evidenciada, mas é na sucessão das imagens que surgem os significados conotados, as sensações criadas pelo filme, as interpretações, as idéias intrínsecas e a imagem feminina construída. Estabelecendo relações entre o figurino e a imagem das personagens na tela, o espectador cria novos signos. Direcionado pelo filme, cria novas imagens e conceitos em acordo com o repertório 
sóciocultural local. O figurino é, portanto, um elemento metafórico, um código de comunicação, de representação que imita a realidade, que faz parte de um jogo de fingimento.

O cineasta italiano Lucchino Visconti definiu o figurino como a pele do personagem, o primeiro contato físico e o encontro semiótico entre o ator e o personagem.

O figurino tem como função principal causar a sensação de estranhamento, å visão inaugural que enfatiza a percepção das sensações, voltando o olhar para as formas femininas. Esse figurino deslocado, ousado, inusitado, usado por Marlene Dietrich no filme analisado, permite ao observador ser sensibilizado por suas características estéticas.

A personagem de Helen Faraday é, pelo figurino, transformada em signo icônico, que se assemelha com a realidade. Para isso o cinema utilizou a analogia perceptiva e os códigos de representação da mulher convencionados na sociedade ocidental. As formas, os tecidos e as texturas, as estampas, a composição do figurino da atriz combinado com a cena, com o cenário contribuem para a encenação, comunicando o status, a condição emocional, a situação da personagem e dirigindo o olhar do espectador, sua leitura e interpretação.

A mulher no cinema é usada para. representar externamente os aspectos mais íntimos do espectador masculino de uma organização social patriarcal. Mas, em Blonde Venus (e em outros filmes), o figurino ajudou a criar também a mulher não-vítima, que tem poder de ação e decisão e acaba se tornando a vilã da diegése. Helen encarnou a ansiedade causada porque se deslocou do papel que lhe é próprio, desafiando paradigmas sociais e culturais, sendo nociva tanto a Edward (e seu filho) quanto ao espectador masculino.

O poder dessas vilãs é equivalente ao das dominadoras fetichistas, como mulheres fálicas, vestidas e fechadas em um figurino-armadura (STEELE, 1997, p. 54). Ela simboliza o objeto culpado dos temas de filmes 'noir' ou a poderosa, a vilã, punida e perdoada (ou não) no final da encenação.

A imagem feminina no cinema é o corpo construído que o espectador transforma, amplia e associa com sua própria realidade cultural, com seu próprio corpo. Por isso as mulheres são incentivadas a imitar essas imagens cinematográficas, a deixar de lado suas tradições locais, seu contexto social e cultural.

\section{CINEMA E MODA}

A relação entre a moda e o cinema existe desde o advento deste e deve ser observada, pois foi pelo figurino que a mulher comum tomou contato com a moda. Jornais, livros, peças teatrais, publicações de moda não tinham o mesmo impacto que mais tarde possuiriam as salas de espetáculos que se transformaram em cinemas. As maisons e lojas passaram a colaborar com as companhias de cinema, emprestando suas roupas em troca de prestígio e propaganda de suas coleções. 
Os estúdios de Hollywood lucraram muito com seus filmes, associandose a famosos estilistas como Poiret, Schiaparelli, Lucille Toray, Lanvin, Morgaleau, Charles Creed, Victor Stiebel e Coco Chanel. O design de Hollywood passou a ser um dos grandes influenciadores da moda. Durante os anos 30 e 40, o figurino dos filmes era tão importante para a divulgação dos mesmos, que os estúdios de Hollywood vendiam antes da estréia, fotos das atrizes (stills) mostrando o que estariam usando na produção. As roupas apareciam então nas revistas de moda e cinema, contribuindo para criar uma aura de poder, de status em torno dos estúdios e das atrizes.

O período de recessão que iniciou os anos 30 passou a ditar a moda. Os ternos escureceram e eram feitos em tecidos mais grosseiros. Vestidos e blusas femininos possuiam ombreiras para aumentar horizontalmente os ombros e eram acinturados abaixo do normal.

O glamour das roupas passou a ser vista apenas nos filmes. O cinema era o escape das dificuldades do período, e as atrizes passaram a encarnar o que a maioria das mulheres desejava ser. Essa transferência de necessidades, de desejos foi o principal motivo para a transformação dessas atrizes em "divindades da beleza", que representavam uma espécie de realeza de Hollywood.

Durante a Segunda Guerra Mundial a Inglaterra implantou a medida 'L85', que restringia o uso de tecidos de lã, seda, rayon, algodão e linho, limitando os estilos mais ousados e o uso de tecidos mais caros. O glamour continuava restrito aos filmes de Hollywood, que mantinha e aumentava os investimentos em produções espetaculares e caríssimas para entreter e distrair o espectador, misturando temas de guerra com mulheres de terninhos e musicais, com mulheres em vestidos deslumbrantes.

Enquanto a mulher comum se vestia seguindo as restrições impostas pela guerra, a mulher no cinema se apresentava com roupas espetaculares, confeccionados com enormes quantidades de tecidos caros.

É nesse contexto que Marlene Dietrich, Greta Garbo, Joan Crawford e Rita Hayworth passaram a encarnar imagens de perfeição, de divas, deusas. Eram subjetividades moldadas em um padrão de beleza, de feminilidade da época. Sua presença na tela estimulava a primeira visão do espectador, liberta de conceitos. Entretanto à medida que o filme avançava, a relação dessas atrizes com a imagem feminina com freqüência tornava-se arbitrária, regida por convenções e estereótipos. Passavam a ser um objeto funcional, símbolo, condicionado por leis e padrões de beleza e tendiam a representar personagens parecidos, de acordo com a imagem que "vendesse" melhor o comportamento da época: Marlene Dietrich - personagens de cabaré com tendência homossexual; Greta Garbo - personagens desafortunadas no amor; Joan Crawford - personagens autobiográficas, que casavam com homens milionários; Rita Hayworth - personagens sensuais que anteciparam as pinups dos anos 50 .

"O olhar masculino determinante projeta sua fantasia na figura feminina, estilizada (...) as mulheres são simultaneamente olhadas e exibidas, tendo sua aparência codificada no sentido de emitir um impacto erótico e visual de forma a que se possa dizer que conota a sua condição de 'para ser olhada' (...) sua presença visual tende a (...) congelar o fluxo da ação em momentos de contemplação erótica" (MULVEY,1973). 


\section{CONCLUSÃO}

Após analisar os filmes selecionados, os resultados foram comparados com as produções cinematográficas atuais (1990 a 2004) para descobrir se a imagem feminina estereotipada ainda está presente. Constatou-se que a mulher no cinema, a atriz, ainda projeta uma imagem para seu espectador e que o figurino continua sendo utilizado para a montagem de uma deusa, de uma estrela, que divide seu espaço com as top models do mundo da moda (em uma espécie de parceria lucrativa para ambas as indústrias). Hollywood ainda mantém os estereótipos femininos reduzidos nas formulações apresentadas a seguir:

- Mulher fraca: passiva, permissiva, heroína, feminina.

Uma linda muther

Filmes: (Pretty woman, 1990);

Que mulher é essa (One night at McCool's, 2001).

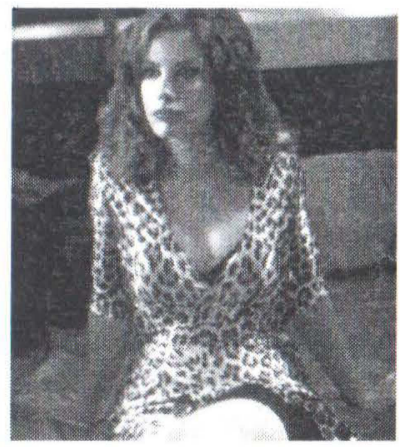

Figura 11 - STILL DO FILME "QUE MULHER É ESSA" FONTE: IMDB

- Mulher forte = bad girl, perigosa, vilã, masculina.

Filmes:

Assédio sexual (Disclosure, 1994); Instinto selvagem (Basic Instinct, 1992); Atração fatal (Fatal Attraction, 1997).

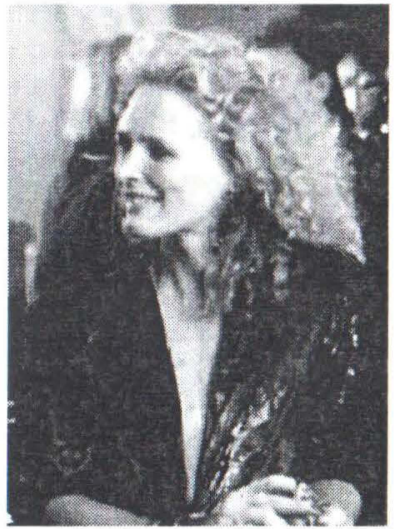

Figura 12 - STILL DO FILME "ATRAÇÃO FATAL" FONTE: IMDB 
Nos filmes atuais o corpo sensual feminino é usado como uma arma de ataque ao poder masculino. Pernas e bustos são moldados em minissaias, vestidos justos, cinta-liga, saltos pontiagudos, sutiãs meia taça e calcinhas pretas (ou a ausência delas). O figurino compõe um uniforme para uma guerra de sedução. São protagonistas predadoras, inescrupulosas e ambiciosas. São protótipos da dominadora fetichista. Seja por assassinato ou por chantagem, roubam o espaço das personagens masculinas.
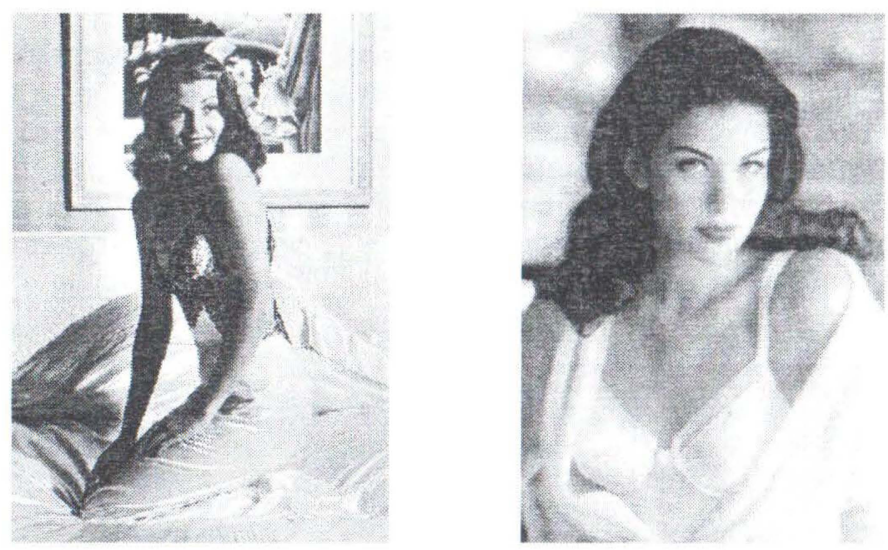

Figura 13 - COMPARAÇÃO DAS IMAGENS DE RITA HAYWORTH E LIV TYLER FONTE: IMDB
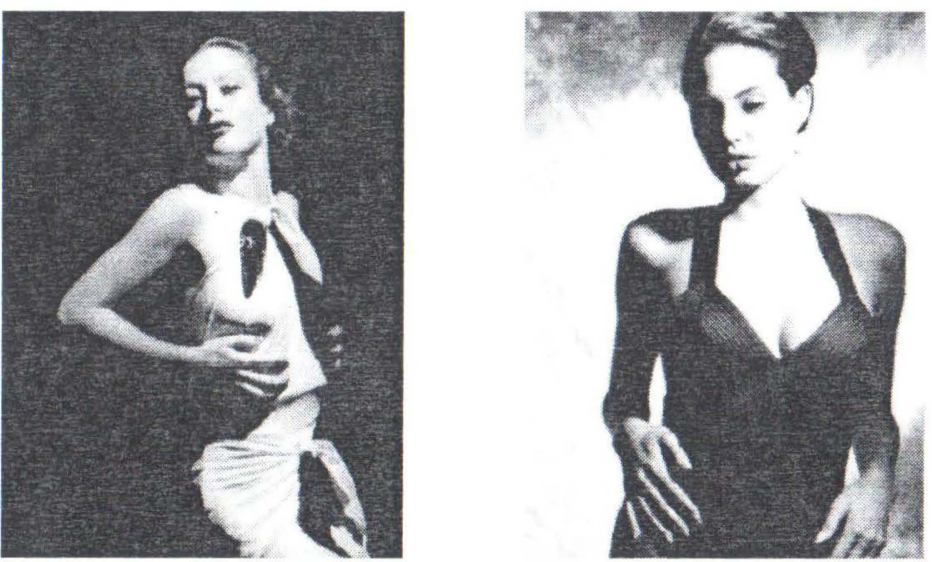

Figura 14 - COMPARAÇÃO DE IMAGENS: JOAN CRAWFORD E ANGELINA JOLIE FONTE: IMDB 
Por isso, nesses papéis, a mulher normalmente é punida; morta, presa, demitida, como um exemplo para outras mulheres: "Estou apenas fazendo o jogo dos homens e sendo punida por isso. Tudo bem!"(frase da personagem Meredith Johnson, interpretada por Demi Moore em "Assédio Sexual").

As danças, os gestos, as características do corpo da mulher em um filme refletem e validam a identidade cultural ocidental.

O corpo é um texto formado por muitos outros textos, não apenas do ambiente cinemâtográfico, mas também do contexto cultural em que esse filme foi originalmente produzido. Entretanto, a criação e a glorificação destes padrões ocidentais de beleza feminina atingem realidades locais, podendo alterar comportamentos e relações sociais. A cultura, o olhar externo, exigiram diferentes características, formas e estilos para a mulher através dos tempos. A imagem cinematográfica da mulher, seu corpo, seu gesto, seu rosto, seu cabelo foram esculpidos para criar e impor o que se denomina de estilo, ou seja, todo o quadro de referência corporal que deverá compor a imagem da mulher "real".
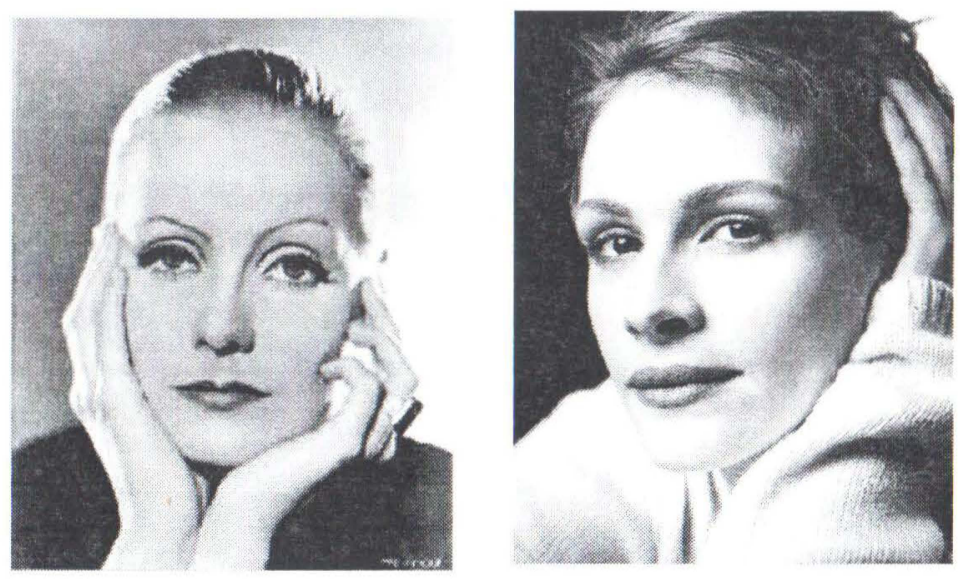

Figura 15 - IMAGENS DE GRETA GARBO E JULIA ROBERTS FONTE: IMBD

Durante o século $X X$, a fotografia, o cinema, a televisão e mais recentemente a computação gráfica transformaram a visão do corpo humano. Os órgãos que percebem e observam este corpo foram potencializados, expandidos, ampliados por instrumentos da mídia terciária (CAMPELO, 1997, p. 31).

A tecnologia empregada no cinema hollywoodiano, exibe atores e atrizes em corpos criados, envolvidos por roupas criadas e transformados em heróis. Representam e exacerbam as lutas, os conflitos do homem e da mulher comuns. Por meio de novas tecnologias de comunicação e de imagem, criouse a possibilidade de uma maior identificação entre o espectador e o personagem. Uma relação diferente do que acontecia nos séculos anteriores com os heróis literários. Os personagens saíram dos livros, de uma estrutura 
bidimensional para uma representação tridimensional de fácil associação.

Nesse contexto, o figurino é uma tecnologia que freqüentemente mantém a personagem feminina inútil e ocupada com a beleza e com a conquista do ator / espectador. Conforme esse estudo procurou demonstrar, o figurino foi e é usado para acentuar a imagem de mulher-espetáculo, construção sóciocultural que pertence à indústria do consumo. Na indústria cinematográfica (apoiada na indústria de moda), o figurino valoriza e ratifica paradigmas sociais que impõem a imagem de mulher aceita, uma mulher bela, objeto de desejo do universo masculino.
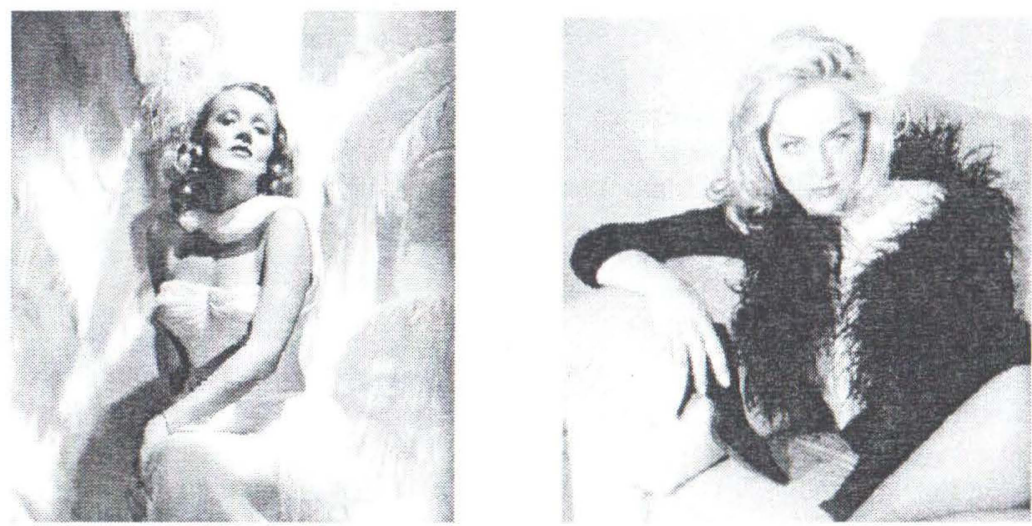

Fifura 16 - COMPARAÇÃO: MARLENE DIETRICH E SHARON STONE FONTE: IMDB

\section{REFERÊNCIAS BIBLIOGRÁFICAS}

CAMPELO, C. R. Cal(e)idoscorpos: um estudo semiótico do corpo e seus códigos. São Paulo: Annablume, 1997.

ETCOFF, N. Lei do mais belo: a ciência da beleza. Rio de Janeiro: Objetiva,1999.

JOLY, M. Introdução à análise da imagem. São Paulo: Papirus, 1996.

LURIE, A. A linguagem das roupas. Rio de Janeiro: Rocco, 1997.

MULVEY, L. Prazer visual e cinema narrativo. In: Xavier, I. (org.). A experiência do cinema. São Paulo: Graal, 1973. p.437 - 453.

STEELE, V. Fetiche: moda, sexo e poder. Rio de Janeiro: Rocco, 1997.

VEBLEN, T. Dress as an Expression of the Pecuniary Culture. In: organizadores. The theory of the leisure class, an economic study of institutions. New York: The Macmillan Company, 1989. 


\section{AGENDA}

\section{Aconteceu ...}

tema é gênero:

. . . as şeguintes defesas de dissertações de mestrado do PPGTE cujo

1. Quem mora no livro didático? Representações de gênero nos livros de Matemática na virada do milênio. Por Lindamir Salete Casagrande e orientada pela Prof ${ }^{a}$. Dr ${ }^{a}$. Marilia Gomes de Carvalho.

2. A invasão dos ciborgues: $A$ influência do ciberespaço nas representações de gênero dos adolescentes. Por Juliana Schwartz, orientada pela Prof ${ }^{a}$. Dr ${ }^{a}$. Sonia Ana C. Leszczynski.

O resumo das dissertações encontram-se no site:

http://www.ppgte.cefetpr.br/dissertacoes/ dis2005.htm

\section{Acontece...}

... nos dias 14, 15, 16 e 17 de agosto de 2005, o 1ํ Simpósio Brasileiro Gênero \& Mídia. O evento será realizado nas dependências do CEFET-PR, Unidade Curitiba, Paraná. Durante o evento acontecerão conferências, mesasredondas, grupos de trabalho e painéis, com os seguintes temas: cinema, fotografia, televisão, rádio, imprensa escrita, internet e multimídia. Para maiores informações consulte o site:

http://www.ppgte.cefetpr.br/simbgn/index.html

. . . dos dias 07 a 10 de novembro de 2005, o Simpósio Nacional de Tecnologia e Sociedade. O evento será realizado nas dependências do CEFET-PR, Unidade Curitiba, Paraná. Estarão acontecendo comunicações com o tema: Gênero, Tecnologia e Sociedade. Os trabalhos podem ser enviados até o dia 29 de agosto de 2005. Para maiores informações consulte o site: www.ppgte.cefetpr.br 


\section{NORMAS DE PUBLICAÇÃO:}

A publicação nos Cadernos de Gênero e Tecnologia é aberta à comunidade científica em geral. Serão aceitos para publicação artigos em português, espanhol e inglês.

Os artigos serão apreciados pela Conselho Editorial do Caderno. O resultado da apreciação será encaminhado via e-mail para os/as autores/as.

Os textos deverão ser compatíveis com o Microsoft Word e ter as seguintes características:

- Tamanho do Papel: A4;

- Número máximo de laudas: 20 laudas;

- Margem Superior, Inferior, Direita e Esquerda: 2,5 cm;

- Espaçamento do Texto: 1,5;

- Espaçamento do Resumo: simples;

- Resumo: 10 linhas no máximo;

- Tipo da Fonte: Times New Roman;

- Tamanho da Fonte: 12;

- Palavras-Chave: 4 no máximo.

Os nomes dos/as autores/ras não deverão aparecer no texto. Os dados dos/as autores/ras (nome completo, filiação institucional, endereço, telefone, email) deverão estar em uma folha de rosto.

O artigo deverá obedecer ao padrão ABNT para bibliografia, citações, tabelas e figuras (gráficos, fotos, e outros). Todas as figuras devem estar em preto-e-branco.

Não serão aceitos artigos que não estiverem nas normas descritas acima.

Os artigos completos, incluindo a folha de rosto, deverão ser enviados para o e-mail cadernogt@ppgte.cefetpr.br. 